\title{
Comparative Evaluation of Blood Parameters in Chronic Periodontitis Patients and Healthy Patients for Signs of Anemia
}

\author{
Dr. Shashikanth Hegde ${ }^{1}$, Dr.Riyas ${ }^{2}$, Dr. Rajesh Kashyap. $S^{3}$, \\ Dr. Arun Kumar M.S ${ }^{4}$ \\ ${ }^{1}$ Prof \& Head, Dept. of Periodontics, Yenepoya dental College \& Hospital, Mangalore, India. \\ ${ }^{2}$ Post Graduate student, Dept. of Periodontics, Yenepoya dental College \& Hospital, Mangalore, India. \\ ${ }^{3}$ Professor, Dept. of Periodontics, Yenepoya dental College \& Hospital, Mangalore, India. \\ ${ }^{4}$ Professor, Dept. of Periodontics, Yenepoya dental College \& Hospital, Mangalore, India.
}

\begin{abstract}
:
Aim: To compare the blood parameters in patients with clinically healthy gingiva and chronic periodontitis for signs of anemia.
\end{abstract}

Materials And Methods: A total of 134 systemically healthy male patients, in the age group 25-50 years, were included in the study. Of these, 67 patients were healthy controls and 67 patients had severe periodontitis. Red blood cell parameters were evaluated from peripheral blood samples.

Statistical Analysis: Data were analyzed by student t test and Mann-Whitney test.

Results: Data analysis shows that patients with chronic periodontitis had lower values of hematocrit, number of erythrocytes, and hemoglobin and increased ESR level compared to healthy group. No remarkable differences in levels of $M C H, M C H C$ and $M C V$ were found between test and control group.

Keywords: Anemia, Chronic Periodontitis, Erythrocyte Sedimentation Rate (ESR), Hemoglobin level (Hb), Red blood cells indices

\section{Introduction}

In India, anemia is a common and serious health disorder among both sexes and all age groups, although it has a higher prevalence among women than men. ${ }^{[1]}$ Anemia is a state of decreased hemoglobin concentration, reduced number of circulating erythrocytes in blood or both. Anemia of chronic disease (ACD) is the second most prevalent anemia after iron deficiency anemia, and occurs in patients with acute or chronic immune activation. Thus, the condition has been termed "anemia of inflammation. ${ }^{[2]}$

Anemia of chronic disease (ACD) is defined as anemia occurring in chronic infections, inflammatory conditions, or a neoplastic disorder, which is not caused by marrow deficiencies or other diseases, and occurring despite the presence of adequate iron stores and vitamins. ACD is a mild-to-moderate, normochromic/normocytic anemia, and is characterized by decreased serum iron and total iron-binding capacity, with normal or increased iron stores. ${ }^{[1]}$

Periodontitis is an inflammatory disease of the supporting tissues of the tooth caused by specific microorganisms in a susceptible host. Just as the periodontal tissues mount an immune inflammatory response to bacteria and their products, systemic challenges with these agents also induce a major vascular response. Chronic periodontitis is the most common form of periodontal disease, which progresses relatively slowly and is more common in adults. ${ }^{[1]}$

The association of anemia and periodontitis has been explored since the early 20th century. Earlier reports have suggested anemia to be a cause, and not a consequence, of destructive periodontitis. Certain cytokines produced during periodontal inflammation can depress erythropoietin production leading to the development of anemia. ${ }^{[2]}$ Thus, periodontitis results in low-grade systemic inflammation, which may cause lower number of erythrocytes and, consequently, lower hemoglobin $(\mathrm{Hb})$ concentration. Evidence indicates that ACD is seen in chronic periodontitis. Though the etiologic factors of both the diseases are different, longstanding chronic inflammation can lead to anemia. ${ }^{[3]}$

Seigel in 1945 was the first to report that decrease in the number of erythrocytes occurred secondary to periodontal disease and arrest or cure of periodontal disease resulted in an increase in erythrocyte count. This marked the beginning of research to evaluate the causal effect of periodontitis in anemia. However, it was Hutter in 2001, which used the term Anemia of chronic disease to describe the anemia observed in periodontitis. ${ }^{[3]}$

The aim of the present study is to probe the association of chronic periodontitis and anemia. To evaluate this, peripheral blood samples were collected and red blood cells (RBC), ESR parameters were measured and compared in male patients with chronic periodontitis and healthy controls. 


\section{Methodology}

The study population consisted of 134 male patients between the age group of 25-50 years, selected from the outpatient department of periodontics, Yenepoya Dental College, Mangalore. The study was approved by Yenepoya University Ethical Committee. The inclusion criteria were as follows: 1) Age group 25 to 50 years 2) Group I- Patients with clinically healthy gingiva with a probing depth of $\leq 3 \mathrm{~mm}$ and gingival index score of $\leq$ $1 \mathrm{~mm}, 3)$ Group II-Chronic periodontitis patients with a probing depth of $\geq 4 \mathrm{~mm}$. The exclusion criteria were as follows: 1) Female patients. 2) Patients with history of systemic disease. 3) History of hospitalization or intake of medications in the last 6 months. 4) Patients with current or past habit of tobacco smoking or chewing. 5) Previous history of periodontal therapy in last 6 months.

67 male patients with clinically healthy gingiva were assigned to the control group and 67 male patients with chronic periodontitis were assigned to the test group. All patients were provided with verbal explanation of the nature of the study, and informed consent was obtained. A detailed systemic and family history was recorded. Gingival and periodontal findings were recorded for each patient and blood parameters were assessed after collection of blood.

\section{Hematological Parameters}

$5 \mathrm{ml}$ of venous blood was drawn from the anti-cubital fossa and collected in a vacutainer. Ethylene diamine tetra acetic acid (EDTA) used as an anticoagulant. The anticogulated blood was used for the analysis of blood parameters. (Figure: 3) The blood parameters analyzed were, Erythrocyte count (RBC), Mean corpuscular volume (MCV), Hemoglobin concentration, Hematocrit (packed cell volume), Mean corpuscular hemoglobin $(\mathrm{MCH})$, Mean corpuscular hemoglobin concentration (MCHC) and Erythrocyte sedimentation rate(ESR). Erythrocyte count, Hemoglobin concentration, Mean corpuscular volume, Mean Corpuscular hemoglobin, Mean corpuscular hemoglobin concentration and hematocrit was measured using an automated hematology analyser.ESR was estimated using Westergren's method.

\section{Results}

The present study was designed for the comparative evaluation of blood parameters in chronic periodontitis patients and healthy patients for signs of anemia. Statistical analyses were performed with software. Means - SD of all the parameters were calculated for both groups. To illustrate differences between groups, a Student $t$ test and Mann-Whitney test, and was considered highly significant $(\mathrm{p}<0.001)$.

Table 1 shows the comparison between RBC count in test and control group. The difference was found to be highly significant ( $\mathrm{p}<0.001)$. The mean $\mathrm{RBC}$ count in test group was $4.87 \pm 0.42 \mathrm{million} / \mathrm{cu} \mathrm{mm}$; in control group RBC count is 5.14 \pm 0.31 million/cu mm. (Table 1 and Fig. 1)

Table 2 shows the comparison between haemoglobinconc: in test group and control group. The difference was found to be highly significant $(\mathrm{p}<0.001)$. The mean haemoglobinconc: in test group was 14.02 $\pm 0.91 \mathrm{gm} / \mathrm{dl}$, in control group haemoglobinconc: is $15.28 \pm 0.65 \mathrm{gm} / \mathrm{dl}$. (Table 2 and Fig. 2)

Table 3 shows the comparison between MCV in test group and control group. The difference was not statistically significant. The mean MCV in test group was $83.46 \pm 5.84$ (fl), in control group MCV is $83.66 \pm 0.65$ (fl), (Table 3 and Fig. 3)

Table 4 shows the comparison between MCHC in test group and control group. The difference was not statistically significant. The mean MCHC in test group was $35.01 \pm 1.46(\mathrm{~g} / \mathrm{dl})$, in control group MCHC is $35.23 \pm 1.05$ (g/dl). (Table 4 and Fig. 4)

Table 5 shows the comparison between $\mathrm{MCH}$ in test group and control group. The difference was not statistically significant. The mean $\mathrm{MCH}$ in test group was $29.20 \pm 2.01$ (pg), in control group $\mathrm{MCH}$ is $29.48 \pm 1.47$ (pg). (Table 5 and Fig. 5)

Table 6 shows the comparison between hematocrit level in test group and control group. The difference was found to be highly significant $(\mathrm{p}<0.001)$. The mean hematocrit level in test group was $40.26 \pm 2.66(\%)$, in control group hematocrit level is $43.03 \pm 2.56$ (\%). (Table 6 and Fig. 6)

Table 7 shows the comparison between ESR count in test group and control group. The difference was found to be highly significant $(\mathrm{p}<0.001)$. The mean ESR count in test group was $8.48 \pm 5.36$ ( $\mathrm{mm}$ at 1 hour), In control group ESR count is $5.12 \pm 2.71$ ( $\mathrm{mm}$ at 1 hour). (Table 7and Fig. 7)

\begin{tabular}{|c|c|c|c|c|c|c|c|}
\hline & \multirow[b]{2}{*}{$\mathrm{N}$} & \multirow[b]{2}{*}{ Mean } & \multirow[b]{2}{*}{ Std. Deviation } & \multicolumn{2}{|c|}{$\begin{array}{l}\text { 95\% Confidence Interval for } \\
\text { Mean }\end{array}$} & \multirow{2}{*}{$\begin{array}{l}\mathrm{t} \text { test } \\
\text { value }\end{array}$} & \multirow[b]{2}{*}{$p$ value } \\
\hline & & & & Lower Bound & Upper Bound & & \\
\hline Test group & 67 & 4.87 & .42 & 4.76 & 4.97 & 4.29 & .000 \\
\hline Control group & 67 & 5.14 & .31 & 5.07 & 5.22 & & $<0.001, \mathrm{HS}$ \\
\hline
\end{tabular}

Table 1: Comparison of RBC count in Test group and Control group 
HEMOGLOBIN

\begin{tabular}{|c|c|c|c|c|c|c|c|}
\hline & \multirow[b]{2}{*}{$\mathrm{N}$} & \multirow[b]{2}{*}{ Mean } & \multirow[b]{2}{*}{ Std. Deviation } & \multicolumn{2}{|c|}{$\begin{array}{l}\text { 95\% Confidence Interval for } \\
\text { Mean }\end{array}$} & \multirow{2}{*}{$\begin{array}{l}\mathrm{t} \text { test } \\
\text { value }\end{array}$} & \multirow[b]{2}{*}{ p value } \\
\hline & & & & Lower Bound & Upper Bound & & \\
\hline Test group & 67 & 14.02 & .91 & 13.80 & 14.24 & 9.23 & .000 \\
\hline Control group & 67 & 15.28 & .65 & 15.12 & 15.44 & & $<0.001, \mathrm{HS}$ \\
\hline
\end{tabular}

Table 2: Comparison of Haemoglobin concentration in Test group and Control group

\begin{tabular}{|c|c|c|c|c|c|c|c|}
\hline & \multirow[b]{2}{*}{$\mathrm{N}$} & \multirow[b]{2}{*}{ Mean } & \multirow[b]{2}{*}{ Std. Deviation } & \multicolumn{2}{|c|}{$\begin{array}{l}95 \% \text { Confidence Interval for } \\
\text { Mean }\end{array}$} & \multirow{2}{*}{$\begin{array}{l}\mathrm{t} \text { test } \\
\text { value }\end{array}$} & \multirow[b]{2}{*}{ p value } \\
\hline & & & & Lower Bound & Upper Bound & & \\
\hline Test group & 67 & 83.46 & 5.84 & 82.03 & 84.88 & .23 & .819 \\
\hline Control group & 67 & 83.66 & 4.04 & 82.67 & 84.64 & & NS \\
\hline
\end{tabular}

Table 3: Comparison of MCV value in Test group and Control group

$\mathrm{MCHC}$

\begin{tabular}{|c|c|c|c|c|c|c|c|}
\hline & \multirow[b]{2}{*}{$\mathrm{N}$} & \multirow[b]{2}{*}{ Mean } & \multirow[b]{2}{*}{ Std. Deviation } & \multicolumn{2}{|c|}{$\begin{array}{l}95 \% \text { Confidence Interval for } \\
\text { Mean }\end{array}$} & \multirow{2}{*}{$\begin{array}{l}t \text { test } \\
\text { value }\end{array}$} & \multirow[b]{2}{*}{$p$ value } \\
\hline & & & & Lower Bound & Upper Bound & & \\
\hline$\overline{\text { Test group }}$ & 67 & 35.01 & 1.46 & 34.65 & 35.37 & 1.00 & .318 \\
\hline Control group & 67 & 35.23 & 1.05 & 34.97 & 35.49 & & NS \\
\hline
\end{tabular}

Table 4: Comparison of MCHC value in Test group and Control group

$\mathrm{MCH}$

\begin{tabular}{|c|c|c|c|c|c|c|c|}
\hline & \multirow[b]{2}{*}{$\mathrm{N}$} & \multirow[b]{2}{*}{ Mean } & \multirow[b]{2}{*}{ Std. Deviation } & \multicolumn{2}{|c|}{$\begin{array}{l}95 \% \text { Confidence Interval for } \\
\text { Mean }\end{array}$} & \multirow{2}{*}{$\begin{array}{l}t \text { test } \\
\text { value }\end{array}$} & \multirow[b]{2}{*}{ p value } \\
\hline & & & & Lower Bound & Upper Bound & & \\
\hline Test group & 67 & 29.20 & 2.01 & 28.71 & 29.69 & .91 & .365 \\
\hline Control group & 67 & 29.48 & 1.47 & 29.12 & 29.84 & & NS \\
\hline
\end{tabular}

Table 5: Comparison of MCH value in Test group and Control group

HEMATOCHRIT

\begin{tabular}{|c|c|c|c|c|c|c|c|}
\hline & \multirow[b]{2}{*}{$\mathrm{N}$} & \multirow[b]{2}{*}{ Mean } & \multirow[b]{2}{*}{ Std. Deviation } & \multicolumn{2}{|c|}{$\begin{array}{l}\text { 95\% Confidence Interval for } \\
\text { Mean }\end{array}$} & \multirow{2}{*}{$\begin{array}{l}\mathrm{t} \text { test } \\
\text { value }\end{array}$} & \multirow[b]{2}{*}{$p$ value } \\
\hline & & & & Lower Bound & Upper Bound & & \\
\hline Test group & 67 & 40.26 & 2.66 & 39.61 & 40.91 & 6.15 & .000 \\
\hline Control group & 67 & 43.03 & 2.56 & 42.40 & 43.65 & & $<0.001, \mathrm{HS}$ \\
\hline
\end{tabular}

Table 6: Comparison of Hematocrit value in Test group and Control group

\begin{tabular}{|c|c|c|c|c|c|c|c|c|}
\hline & \multirow[b]{2}{*}{$\mathrm{N}$} & \multirow[b]{2}{*}{ Mean } & \multirow[b]{2}{*}{$\begin{array}{c}\text { Std. } \\
\text { Deviation }\end{array}$} & \multirow[b]{2}{*}{ Median } & \multicolumn{2}{|c|}{$\begin{array}{l}95 \% \text { Confidence Interval } \\
\text { for Mean }\end{array}$} & \multirow[b]{2}{*}{$\begin{array}{l}\text { Mannwhitney } \\
\text { test }\end{array}$} & \multirow[b]{2}{*}{ p value } \\
\hline & & & & & $\begin{array}{l}\text { Lower } \\
\text { Bound }\end{array}$ & $\begin{array}{l}\text { Upper } \\
\text { Bound }\end{array}$ & & \\
\hline Test group & 67 & 8.48 & 5.36 & 7.00 & 7.17 & 9.79 & 4.57 & .000 \\
\hline Control group & 67 & 5.12 & 2.71 & 5.00 & 4.46 & 5.78 & & $<0.001, \mathrm{HS}$ \\
\hline
\end{tabular}

Table 7: Comparison of ESR value in Test group and Control group 


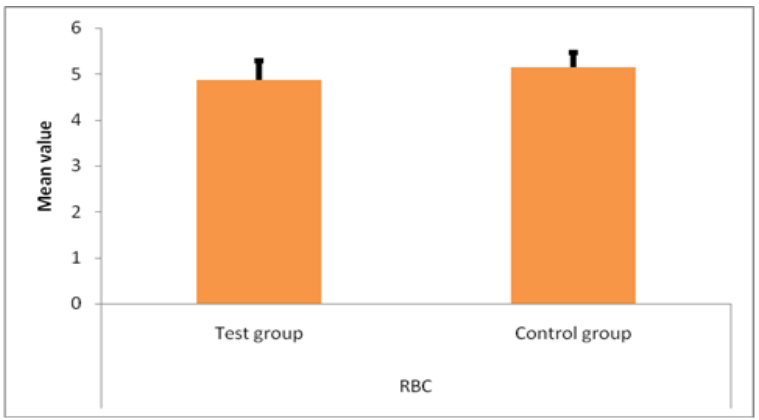

Fig 1: Comparison of mean value of RBC count (million/cu mm) in Test group and Control group

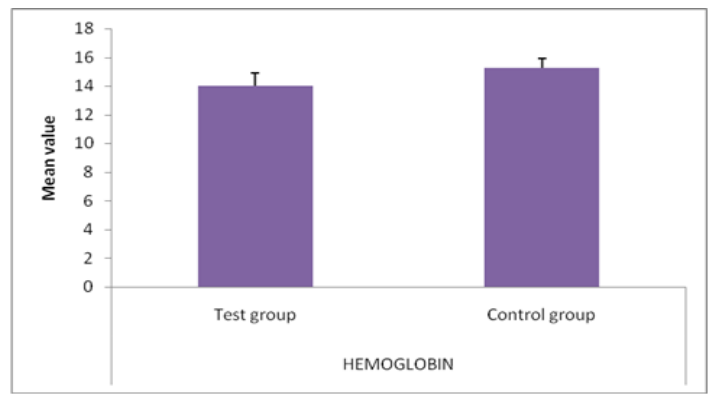

Fig 2: Comparison of mean value of Haemoglobin concentration ( $\mathrm{g} / \mathrm{dl})$ in Test group and Control group

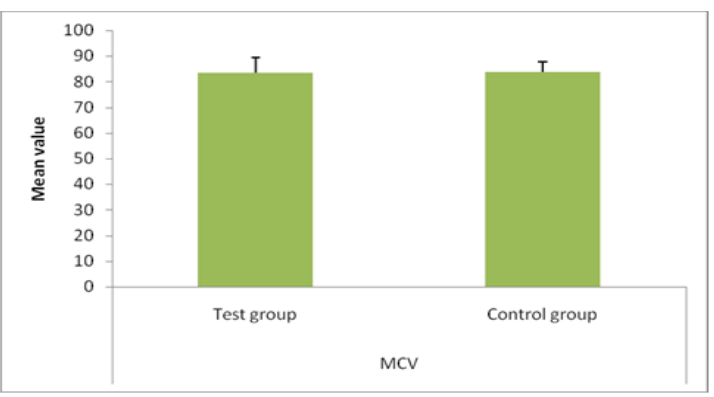

Fig 3: Comparison of mean value of MCV (fl) in Test group and Control group

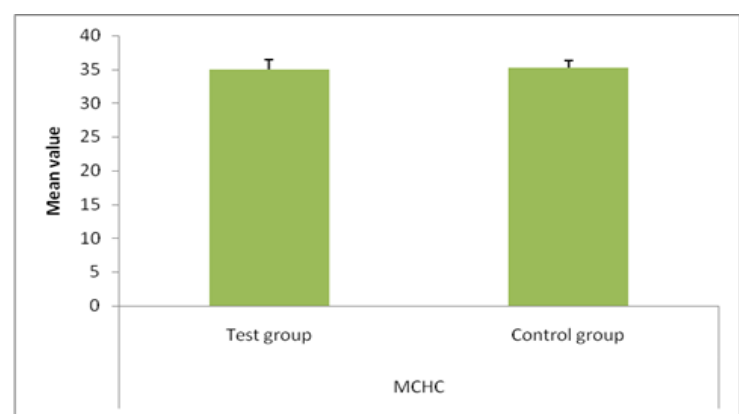

Fig 4: Comparison of mean value of MCHC (g/dl) in Test group and Control group

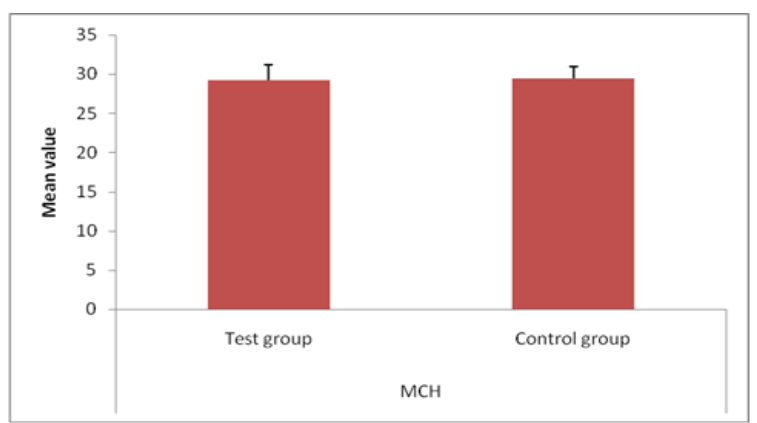

Fig 5: Comparison of mean value of $\mathrm{MCH}(\mathrm{pg})$ in Test group and Control group 


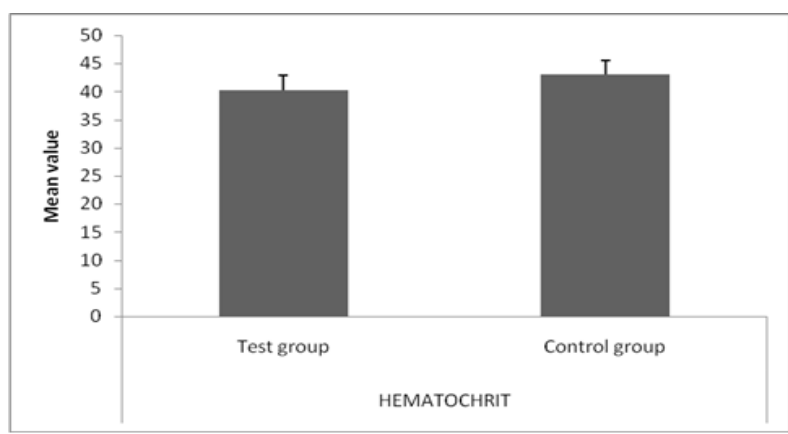

Fig 6: Comparison of mean value of Hematocrit (\%) in Test group and Control group

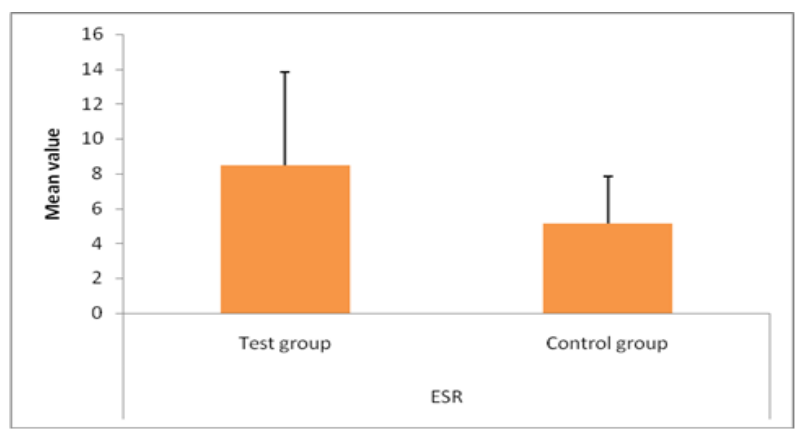

Fig 7: Comparison of mean value of ESR (mm at 1 hour) in Test group and Control group

\section{Discussion}

Anemia is common condition and can be caused by various factors. It can also exist as a co-morbidity along with many chronic inflammatory infectious diseases, neoplasia and autoimmune disorders, where it is referred to as Anemia of chronic diseases (ACD). ${ }^{[4]}$ Anemia of chronic disease is known to be mediated by cytokines released in the blood stream due to underlying chronic inflammatory/infectious conditions. ${ }^{[5]}$ Additionally hepcidin, an iron binding protein, plays an important role in the pathogenesis of ACD. This protein is upregulated by IL-6. This subsequently reduces iron uptake for erythropoiesis. Cytokines also reduce erythropoietin, a hormone that regulates erythropoiesis, leading to anemia. It is well established that periodontitis, being a chronic inflammatory disease, causes an elevation in numerous systemic inflammatory markers like IL-6, IL-14 and can have systemic effects. ${ }^{[6]}$ The association between anemia and periodontitis has been studied since a long time but with varying results. In a study, it was reported that anemia plays a direct role in the etiology of periodontal disease. ${ }^{[7,8]}$ In contrary, Seigel et al demonstrated that anemia occurred as a result of destructive periodontal disease. ${ }^{[9]}$

Female patients were not included in the study to rule out anemic signs due to iron deficiency anemia. ${ }^{[9,}$ ${ }^{10]}$ Smokers were not included, because there is evidence suggesting that smoking is a co-factor for development of periodontitis. ${ }^{[11]}$ Also Erdemir et al ${ }^{[11]}$ demonstrated that smokers having periodontitis with ACD had lower blood parameters when compared to non-smokers with ACD.Other studies evaluating the relationship of ACD and periodontitis were either case-control studies or interventional studies and hence prevalence of ACD was not reported. ${ }^{[8-11]}$

In the present study $\mathrm{RBC}$ count showed a highly significant $(\mathrm{P}<0.001, \mathrm{t}=4.29)$ relationship in patients with periodontitis, when compared to individuals with clinically healthy gingiva. The mean RBC counts were below the normal range $(4.4-5.7 \times 106 / \mathrm{mm} 3)$ in periodontitis patients when compared to control group. Similar results were shown in studies conducted by Patel et $\mathrm{al}^{[1]}$, Gokhale et al ${ }^{[10]}$, Yamamota et $\mathrm{al}^{[12]}$, Malhotra et al ${ }^{[13]}$ Anand et al $^{[14]}$ Virdi et al ${ }^{[15]}$ and Kolte et $\mathrm{al}^{[16]}$ On the contrary, no significant co-relation was found in between RBC count and periodontitis cases in a study conducted by Nair et al ${ }^{[17]}$. In a study, Hutter et al has suggested that periodontitis may cause lower numbers of erythrocytes and consequently lower haemoglobin levels. The pathogenesis was reported to be similar as for rheumatoid arthritis i.e. depressed erythropoiesis by systemically circulating pro-inflammatory cytokines resulting from local chronic inflammatory process. Cytokines such as interleukin-1 (IL-1), interleukin -6 (IL-6), tumor necrosis factor- $\alpha$ (TNF- $\alpha$ ) and interferons are hypothesized to be involved in the maintenance of red blood cell production or stability. Many studies have shown a correlation between inflammation, elevated circulating cytokines and anemia in patients and in mice, but whether these inflammatory cytokines act alone or regulate other pathways that are important for red blood cell production is unclear. ${ }^{[18]}$ 
In the present study $\mathrm{Hb}$ concentration showed a highly significant $(\mathrm{P}<0.001, \mathrm{t}=9.23)$ relationship in patients with periodontitis, when compared to individuals with clinically healthy gingiva. The mean $\mathrm{Hb}$ concentration was below the normal range $(14.0-17.4 \mathrm{~g} / \mathrm{dL})$ in periodontitis patients when compared to control group. This can be attributed to the significantly lower number of RBC's. Similar results were shown in studies conducted by Gokhale et al ${ }^{[10]}$, Malhotra et al ${ }^{[13]}$, Virdi et al ${ }^{[15]}$, Nair et al ${ }^{[17]}$, Anand et al ${ }^{[14]}$ and Jenabian et al ${ }^{[19]}$. On the contrary, no significant co-relation was found in between Hbconcentration and periodontitis cases in a study conducted by Aljohani et al. ${ }^{[20]}$

In the present study hematocrit showed a highly significant $(\mathrm{P}<0.001, \mathrm{t}=6.15)$ relationship in patients with periodontitis, when compared to individuals with clinically healthy gingiva. The mean Hematocrit value were below the normal range $(42-52 \%)$ in periodontitis patients when compared to control group. This can be attributed to the significantly lower number of RBC's. Depressed MCV values suggest microcytosis most commonly caused by iron deficiency, and elevated levels of MCV suggest macrocytosis caused by vitamin deficiency. MCV was in the normal range in both the groups. Therefore, the lower value of hematocrit can attributed to the significantly lower number of RBC' $\mathrm{s}^{[10]}$ Similar results were shown in studies conducted by Gokhale et $\mathrm{al}^{[10]}$, Malhotra et $\mathrm{al}^{[13]}$, Jenabian et al ${ }^{[19]}$, Anand et $\mathrm{al}^{[14]}$, and Nair et $\mathrm{al}^{[17]}$.

In the present study ESR showed a highly significant $(\mathrm{P}<0.001, \mathrm{t}=4.57)$ relationship in patients with periodontitis, when compared to individuals with clinically healthy gingiva. The mean ESR levels for periodontitis patients were higher while compared to healthy individuals. Similar results were shown in studies conducted by Prakash et al ${ }^{[2]}$, Virdi et al ${ }^{[15]}$, Nair et al ${ }^{[17]}$, and Anand et al ${ }^{[14]}$. In test group ESR values had been increased, suggesting of chronic infection. If hematocrit is reduced, as in anemia, red cell aggregates sediment faster, thus the severity of anemia correlates with the ESR . The ESR is a traditional parameter in medicine of any given inflammatory process. It provides a multi-factorial measure of the systemic response to an infectious or inflammatory disease, i.e. a change in the plasma concentration of several inflammation related proteins, that affect the formation of rouleaux by erythrocytes, and which subsequently precipitate (sedimentation). However, this parameter of inflammation seems of limited use as diagnostic tool in periodontitis to measure the systemic involvement. ${ }^{[15]}$

In the present study, MCV, MCH, MCHC showed no significant co-relation with the periodontitis patients, when compared to individuals with clinically healthy gingiva. Similar results were shown in the studies conducted by Gokhale et al ${ }^{[10]}$, Malhotra et al ${ }^{[13]}$, Jenabian et al ${ }^{[19]}$, and Nair et al. ${ }^{[17]}$

Within the limitations of the present study, it can be stated that chronic periodontal diseases are associated with alterations in the hematological parameters which is hemoglobin, erythrocyte sedimentation rate and red blood cells. These findings may be related to the elevated levels of pro-inflammatory cytokines in plasma of periodontitis patients suppressing erythropoiesis. The present study has paved the path for future studies, with a larger study population for a longer period of time to further validate the association between periodontal disease and anemia.

\section{Conclusion}

The following conclusions were arrived at from this study arelower number of erythrocytes (RBS's), hematocrit, hemoglobin in periodontitis patients compared to healthy individuals, Increased ESR levels in Test group compared to control group and no remarkable differences in levels of $\mathrm{MCH}, \mathrm{MCHC}$, and MCV were found between Test group and Control group.Thus based on this results it can be concluded that, like any other chronic condition, chronic periodontitis can lead to anemia.

\section{Acknowledgements}

I express my gratitude to Dr. Rajesh H. (Dept. of Periodontics) and Dr. Sheriff M.H. (Dept. of Pathology) for the guidance and help.

\section{References}

[1]. Patel MD, Shakir QJ, Shetty A. Interrelationship between chronic periodontitis and anemia: A 6-month follow-up study. J Indian SocPeriodontol 2014; 18:19-25.

[2]. Weiss G, Goodnough LT. Anemia of chronic disease. N Engl J Med 2005; 352:1011-1023.

[3]. Anand N, Chandrasekar SC. Dembla G. Anemia of Chronic Disease and Periodontitis. Indian Journal of Multidisciplinary Dentistry.2011; 1(2):82-85.

[4]. Yu lu S, LiewEng H. Dramatic recovery from severe anemia by resolution of severe periodontitis. J Dent Sci 2010; 5(1):41-46

[5]. Means RT, Krantz SB. Progress in understanding the pathogenesis of the anemia of chronic disease. Blood 1992; 80:1639-1647.

[6]. Newman MG, Takei HH, Klokkevold PR, Carranza FA. 10th ed. Carranza's Clinical Periodontology. Missouri. Elsevier, 2006.

[7]. Chawala TN, Kapoor KK, Teotia SPS, Singh NK.Anemia and Periodontal Disease, A Correlative Study. J Indian Dent Assoc 1971; 43; 67-78.

[8]. Hutter JW, Van der Velden U, Varoufaki A, Huffels RAM, Hoek FJ, Loos BG. Lower number of erythrocytes and lower levels of hemoglobin in periodontitis patients compared to control subjects. J ClinPeriodontol 2001; 28:930-936.

[9]. Seigel EH. Total erythrocyte, leukocyte and differential white cell counts of blood in chronic periodontal disease. J Dent Res 1965 ; $24: 270-271$. 
[10]. Gokhale SR, Sumanth S, Padhye AM. Evaluation of blood parameters in patients with chronic periodontitis for signs of anemia. J Periodontol 2010; 81:1202-1206.

[11]. Erdemira EO, Nalcacib R, Caglayan O. Evaluation of Systemic Markers Related to Anemia of Chronic Disease in the Peripheral Blood of Smokers and Non-Smokers with Chronic Periodontitis. Eur J Dent. 2008; 2: 102-109.

[12]. Yamamoto T, Tsuneishi M, Furuta M, Ekuni D, Morita M, Hirata Y. Relationship between decrease of erythrocyte count and progression of periodontal disease in rural Japanese population. J Periodontol 2011; 82:106-113.

[13]. Malhotra R, Kapoor A, Grover V, Grover D, Kaur A. Effect of scaling and root planing on erythrocyte count, hemoglobin and hematocrit in patients with chronic periodontal disease. J Dent Hyg. 2012; 86(3):195-203.

[14]. Anand PS, Sagar DK, Ashok S, Kamath KP. Association of aggressive periodontitis with reduced erythrocyte counts and reduced hemoglobin levels. J Periodontal Res. 2013; 11:1-10.

[15]. Virdi H K.Hematological Parameters- A Diagnostic Mirror For Periodontitis. Indian J Dent Sci.2013; 5(2):45-48

[16]. Kolte R A, Kolte A P, Deshpande N M. Assessment and comparison of anemia of chronic disease in healthy subjects and chronic periodontitis patients: A clinical and hematological study. J IndSoc Periodontol.2014; 18(2):183-186.

[17]. Nair S K, FaizuddinM,JayanthiD.Anemia and Periodontitis: An Enigma ?.JDMS.2013; 11(4):71-78.

[18]. Kalburgi N B, Koregol AC, Muley A, Warad S, patilSandeep.Anemia of chronic disease, periodontal diseases and tobacco use: an association based on hematological parameters. ijomp.2013; 4(2):18-23.

[19]. Jenabian N, Sattari F D, Salar N, Bijani A, Ghasemi N. The relation between Periodontitis and Anemia Associated Parameters. Dentomaxillofac Radiol.2013; 2(3): 27-33.

[20]. Aljohani HA. Association between hemoglobin level and severity of chronic periodontitis. JKAU Med Sci. 2010; 17 (1): $53-64$

[21]. Prakash S, Dhingra K, Priya S. Similar hematological and biochemical parameters among periodontitis and control group subjects. Eur J Dent. 2012; 6(3):287-94. 